\title{
La influencia del medio gaseoso en la composición de fases y propiedades del clínker de cemento portland blanco
}

\author{
IWAN F. PONOMAREW Y otrOS \\ Silikattechnik, $n^{\circ}$ 4, abril 1970, págs. 121 y 122
}

La atmósfera gaseosa existente en el horno es uno de los factores que influyen esencialmente en la composición de las fases y en la estructura y propiedades fisicomecánicas del clínker de cemento portland. El IV simposio internacional sobre cuestiones relacionadas con la química del cemento consideró que era necesario un análisis minucioso de la influencia de la atmósfera gaseosa del horno en el proceso de la formación del clínker, porque los resultados de dicho análisis deben fomentar el desarrollo teórico y práctico de la química-física del cemento.

El carácter de la atmósfera gaseosa del horno tiene una importancia especial en la tecnología del cemento portland blanco. Por esta causa los autores analizaron la influencia de la atmósfera oxidante, neutra y reductora en la formación del clínker y las propiedades del cemento portland blanco.

El crudo se preparó con materias primas suministradas por la fábrica de cementos Schurow, produciéndose un clínker con valores $\mathrm{KH}=0,85 \mathrm{y} \mathrm{n}=3,5$ (standard de cal según Kind y Jung y módulo de silicato). El contenido de óxido de hierro en el clínker fue de $0,6 \%$. Las muestras se clinkerizaron en un horno tubular Pt-Rh con atmósfera gaseosa regulable construido exprofeso para este trabajo. Para fijar la composición de fases y la estructura del clínker de acuerdo con la elevada temperatura de cocción $\left(1.450^{\circ} \mathrm{C}\right)$ el clínker se enfrió rápidamente en agua.

Un 5,5\% de elevación en la blancura, como resultado de la cocción en atmósfera reductora, hay que atribuirlo a alteraciones en la composición de fases y en la estructura de la fase aluminoferrítica.

Por análisis radiográficos y petrográficos se comprobó que el carácter reductor del medio gaseoso impide la disolución de los aluminatos en los aluminoferritos cálcicos durante la cocción del crudo favoreciendo así la formación de combinaciones de alto contenido en hierro, que en su composición se aproximan a la fórmula $\mathrm{C}_{6} \mathrm{AF}_{2}$. Además, también se fomenta la separación de aluminatos cálcicos libres en grandes proporciones. Asimismo, en los productos del proceso de cocción se forman iones $\mathrm{Fe}^{2+}$ debido a la acción reductora del medio gaseoso, los cuales manifiestan una capacidad colorante notablemente menor que los iones $\mathrm{Fe}^{3+}$.

El distinto efecto colorante que provocaron los iones del hierro bi y trivalente en las mues- 
tras analizadas, tiene su explicación en las propiedades físicas no uniformes de los iones. Según la teoría de N. Bohrs, la absorción de los rayos luminosos del espectro visible está directamente relacionada con la existencia de capas polarizadas deformadas de electrones en la combinación absorbida.

Cuanto más intensamente se expresa la polarización de la capa de electrones del ion, tanto más capaz es el ion de absorber rayos luminosos. La polarización del ion se expresa por el desplazamiento de su núcleo y de los electrones. La envolvente de electrones de iones polarizados está aplastada en forma plana y deformada.

Como consecuencia se ha trastornado la simetría de los electrones de la estructura del ion. Como es sabido, aumenta rápidamente la acción polarizadora del ion con el aumento de su carga y con la disminución de su radio. Según referencias (2) el radio del ion de hierro $\mathrm{Fe}^{2+}$ es $=0,83 \AA$ y el del ion $\mathrm{Fe}^{3+}=0,67 \AA$. Según esto, la acción polarizadora del ion $\mathrm{Fe}^{2+}$ sobre aniones de oxígeno próximos es considerablemente más débil que la del ion $\mathrm{Fe}^{3+}$. Este estado de cosas motiva también su diferente capacidad para la absorción de rayos luminosos.

T A B L A 1

Contenido de blanco del clinker (\% en comparación con $\mathrm{BaSO}_{4}$ ), cocido en atmósfera oxidante neutral reductora

\begin{tabular}{llll}
\hline 75,4 & 78,7 & 80,9 \\
\hline
\end{tabular}

A fin de aclarar el carácter de las relaciones mutuas entre el ion hierro y la estructura atómica que le rodea, se fotografiaron espectros de la resonancia paramagnética electrónica (EPR) de clínkeres que se habían cocido tanto en medios gaseosos oxidantes como reductores.

Todos los espectros (fig. 1) muestran en la parte izquierda un máximo bien marcado con un factor $g$ de 4,26, que es característico del ion de hierro trivalente, que se halla en coordinación tetraédrica. La intensidad de este máximo es considerablemente menor en el clínker cocido en atmósfera reductora que en el clínker cocido en atmósfera oxidante. Esto apoya el hecho de que el carácter reductor del medio gaseoso favorece en el clínker una disminución del contenido en iones de hierro trivalentes en coordinación tetraédrica.

Además existen en la curva de resonancia 1 en la zona alta del espectro, seis líneas bien separadas de una estructura superfina del espectro, que hablan de una reacción de los iones de $\mathrm{Fe}^{3+} \mathrm{y} \mathrm{Al}^{3+}$ en los aluminoferritos cálcicos (3). En el espectro del clínker obtenido en atmósfera reductora desaparece la estructura superfina del espectro y en su lugar se produce una señal marcada claramente con un factor $g$ de 2,004, que es característico de los iones $\mathrm{Fe}^{3+}$ en coordinación octaédrica. La capacidad colorante ha disminuido.

Para la investigación del proceso de sinterización de un crudo de cemento cocido en distintos medios gaseosos, se procedió a realizar análisis termográficos. Los resultados se reproducen en la figura 2. Al cocerse una mezcla en atmósfera reductora se observa un máximo del efecto exotérmico para $t=1.260^{\circ} \mathrm{C}$, mientras que este máximo al cocerse en atmósfera oxidante normal no se observa hasta $t=1.290^{\circ} \mathrm{C}$. 
Según el carácter de la modificación en la conductibilidad eléctrica puede suponerse que la atmósfera gaseosa reductora disminuye la temperatura a la que aparece la fase líquida, reduciéndola en $60^{\circ} \mathrm{C}$. Esto se explica porque en la cocción reductora el $\mathrm{Fe}_{2} \mathrm{O}_{3}$ existente en el crudo pasa en parte a $\mathrm{FeO}$. $\mathrm{El} \mathrm{FeO}$ forma con el ácido silícico un eutéctico.

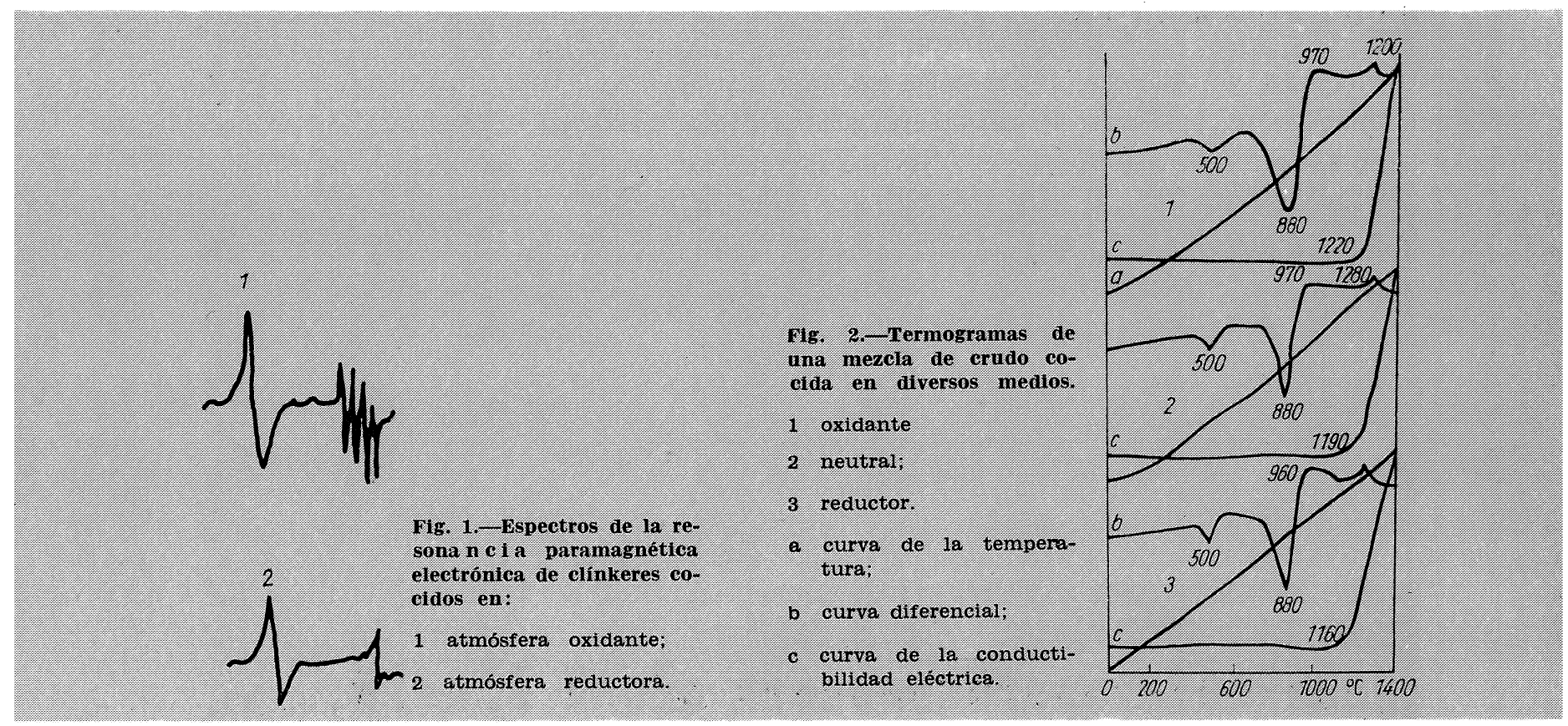

Pruebas fisicomecánicas han demostrado que la influencia nociva del óxido de hierro (II) en los valores de la resistencia del cemento se atenúa bastante enfriando el cemento rápidamente en agua. Este enfriamiento impide la disolución del óxido de hierro (II) en los silicatos tri y bicálcico y hace posible la fijación del $\mathrm{FeO}$ en la fase vítrea. Como consecuencia de esto mejoran los valores característicos de la resistencia mecánica del cemento.

Pruebas bajo condiciones reales de producción realizadas en la fábrica de cemento Schurow, confirmaron la posibilidad de aumentar en $5 \%$ el contenido de blanco del clínker mediante cocción en atmósfera débilmente reductora. El contenido de $\mathrm{CO}+\mathrm{H}_{2}$ de los gases de escape era de 1,5 y $2 \%$.

Los valores de la resistencia de un cemento procedente de clínker cocido en atmósfera débilmente reductora fueron un $10 \%$ superiores a los de un material cocido en atmósfera oxidante con arreglo al método tradicional. El aumento de la resistencia se explica por alteraciones en la estructura cristalina fina de los principales minerales del clínker y que hay que achacar a la cocción en atmósfera reductora. Esto se confirma por análisis radiográficos y electronicoparamagnéticos. Los elementos individuales de la estructura de los minerales se deforman más intensamente, lo cual conduce a la aparición de tensiones adicionales en la red cristalina de los minerales (4). Como consecuencia de esto se facilita la desintegración de la estructura bajo la influencia de los dipolos del agua y de los iones hidróxilo e hidrógeno. De este modo se intensifica la actividad hidráulica del clínker. 
Resumiendo, parece que es conveniente, para la fabricación de un cemento portland blanco, recomendar la cocción del clínker en atmósfera débilmente reductora.

\section{B I B L I O G R A F I A}

(1) Nurse, R. W.: The Chemistry of Cement. Cement, Lime and Gravel (1963) 8, 38.

(2) BokI, G. B.: Einführung in die Kristallographie (russ.) Isd. M G U 1954.

(3) SARINow, M. M., und Schekunow, L. D.: Die elektronische paramagnetische Resonanz in Kristallen (russ.) Sammelwerk "Paramagnetische Resonanz". Isd. Kasansk. Univ. 1964.

(4) Sytschew, M. M., KonneJew, W. I., und FJodorow, N. F.: Alit und Belit im Portlandzementklinker (russ.) Stroiisdat, Moskau/Leningrad 1965.

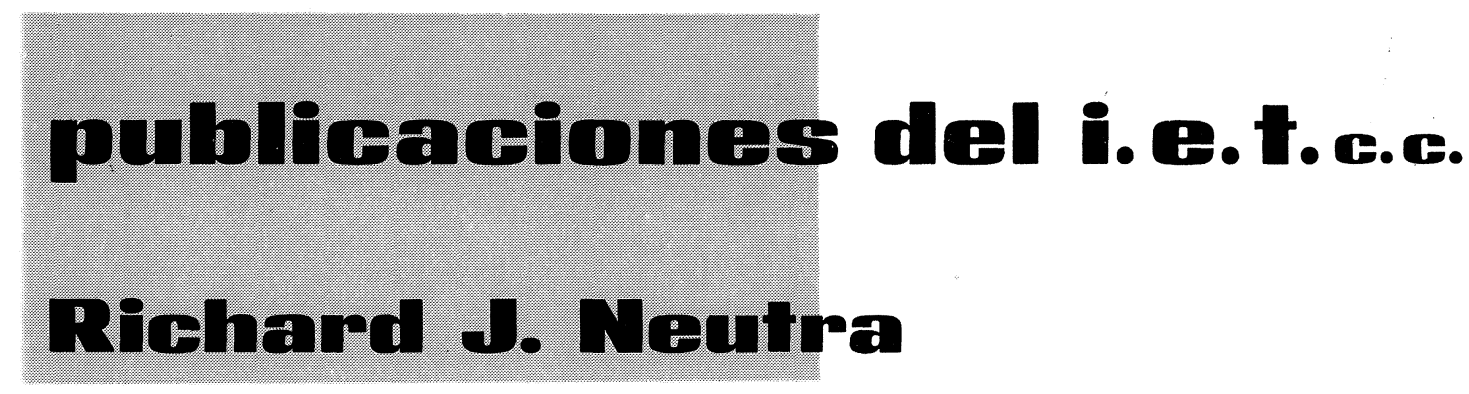

El Instituto Eduardo Torroja, por expreso deseo de su autor, publica, con orgullo, este lujoso libro. En él aparecen expuestas las originales ideas de Neutra sobre todos los aspectos y facetas de su genial creación de extraordinario arquitecto,' extendidas por casi todos los países del mundo.

Por primera vez, se presenta Richard J. Neutra, en una visión integral de su recia personalidad arquitectónica, al ofrecer al lector, simultáneamente, su vida, su pensamiento y su obra. Porque, a lo largo de los sucesivos capítulos, se nos va mostrando su forma de hacer y pensar a través de sus conferencias, de sus realizaciones más destacadas o de sus más recientes escritos.

Y por todo ello, esta publicación constituye la más expresiva muestra de la arquitectura humanistica neutraniana, y sin duda, también, la más amena y actual de todas sus publicaciones.

Este volumen de $27,5 \times 21,5 \mathrm{~cm}$, encuadernado en tela y presentado con gran brillantez, consta de 240 páginas y numerosos planos, croquis y dibujos originales, así como de un gran número de magníficas fotografías. En su última página aparece una graciosa caricatura del autor visto por "Ras", seudónimo que utiliza el arquitecto español Eduardo Robles Piquer.

Precios: España, 1.350 ptas.; extranjero, \$ 27. 